\title{
Gregorio José de Merlos
}

Introducción.-Escrito ante la Rea? Audiencia de Chuquisaca.

INTRODUCCION

El movimiento del cacique don Jose Gabriel Túpac Amaru dió como consecuencia que el clero tomase, de inmediato, dos actitudes diferentes: de un lado, los eclesiásticos que repudiaron abiertamente la rebelión y lucharon contra los alzados; del otro, los que simpatizaban con el levantamiento. Ambos estaban unidos espiritualmente en lo que al aspecto religioso se refiere; y separados, en lo concerniente a su vasallaje ante la autoridad civil (1). Pero, existencadernás biros matices que serán estudiados en ocasión diștintáe Puccinelli Converson

Recalcar este distanciamiento entre las autoridades civiles y religiosas, y esta interior división entre los eclesiásticos, durante los sucesos ocurridos allá por los años de 1780, es de suma importancia para comprender con claridad otros acontecimientos anteriores y posteriores, pues los sacerdotes tenían un gran ascendiente sobre los indígenas, debido tanto a las tareas de su sacro ministerio cuanto de su diario contacto con los Indios. Estos los consideraron, en general, como un grups social dirigente más justo y comprensivo que el de los funcionaries civiles. Por esto, reza un documento de lá época, sucedió durante la rebelión de Túpac Amaru (y asimismo en otros movimientos) que las huestes alzadas "se amansasen con la predicación de los sacerdotes. En los mayores aprietos siempre los sacerdotes eran embajadores, hacían el razonamiento a

(1) Este aspecto ha sido tocado en el capítulo denominado "Actitud del Clero", de mi ensayo "La robelión de Túpac Amaru". Fondo de Cultura Económica de México, 1947, cap. XVI, p. 98-105. 
los indios, y al yaya (sacerdote) nunca lo apresaban, antes rogábanles que a los españoles les dijesen lo que ellos querían, y volvían con la respuesta" (2).

Los eclesiásticos leales o se quedaron en sus Curatos, cumpliendo premiosas exigencias de su ministerio, arrostrando los consiguientes riesgos, o huyeron a las principales ciudades y villas (Cusco, La Paz, Chuquisaca o La Plata, Puno, Potosí, etc.) defendidas por las fuerzas leales a las autoridades del Rey; mientras los eclesiásticos simpatizantes del movimiento permanecieron en sus Curatos, sin desconocer la superior autoridad de sus Prelados ni, aparentemente, la de los funcionarios peninsulares, pero ayudando con su esfuerzo y dinero al incremento de la rebelión. Y cuando algunos se declararon explícitamente contra las autoridades, decían que su lealtad al Rey hacía que abominasen de aquellos malos funcionarios, que desftguraban las justas leyes de la metrópoli. En el fondo, estaban en un grave aprieto; pues por motivos de su estado no podían hacer pública adhesión de su simpatías, puestos ante la encrucijada de sus personales inclinaciones y de su volos específicos. En este grupo se encuentra la persona del eclesiástico doctor don Gregorio José de Merlos, quien en 1780 era cura del pueblo de Macha, provincia de Chayanta, arzobispado de La Plata o Chuquisaca (perteneciente al novísimo virreinato de Buenos Aires) (3). $\AA$ su lado es necesario enumerar a eclesiásticos como el presbítero don Iosé Vásquez de Velasco, el cura de Asillo don José Maruripel Clérigódon IEldtorEscobar, el padre Antonio Chávez, el cura deJPomacanghtidenl Gregrarien Yénez, el de Accha Hanansaya don Tomás Olazu, los dominicos fray Isidro Rodríguez, fray Gregorio de Santa Cruz, fray Hermenegildo Camargo y otros de muy larga enumeración. El cura de la doctrina de Pampamarca, don Antonio López de Sosa, estaba entre los sospechosos de simpatizar, y de haber colaborado, con el cacique Túpac Amaru; y hasta se llegó a desconfiar del egregio tacneño y ejemplar eclesiástico don Ignacio de Castro, uno de los más notables peruanos del siglo XVIII. Entre los prelados fueron insistentes las sopechas, y directas aunque ocultas las acusaciones (ante el propio virrey Jáuregui) contra el muy distinguido obispo arequipeño, futuro arzobispo de Granada, don Juan Manuel de Moscoso y Peralta.

Sin embargo, por excepción se llegó a tener prelados apócrifos comp el "obispo" Nicolás Villca, natural de la hacienda Pachamachay, doctrina

(2) Estado del Perú. por Rafeel José Sahuaraura Titu Atauchi.-Col. Loayza serie I, tomo V.Imp. Miranda, Lima 1944, pi 55 , nota No 31 (de Sahuaraura).

(3) Véase el mapa del Obispado del Cusco y del Obispado de La Paz dependiente del arzobispado de Chuquisaca o La Plata. 
de Challabamba, jurisdicción de la provincia de Paucartambo, de propiedad del prominente cusqueño don Antonio Ugarte, como lo manifiesta el obispo Moscoso y Peralta en carta al obispo de La Paz don Gregorio Francisco del Campo (4); o f́lalsos sacerdotes como el pretendido jesuíta Anselmo Alvisto y Zamalloa.

El documento que más adelante se publica es un inédito ten mi poder) que consta de 10 fojas, en donde el eclesiástico Merlos recusa al fiscal don José de Castilla, documento legalizado ante el escribano don Félix Paravisino, en Chuquisaca el 5 de diciembre de 1776, y con certificación ante los escribanos Terrasas y Guerra Michel, cuando Merlos era cura y vicario de Guachacalla de Carangas. Los motivos de la inquina del Fiscal contra el eclesiástico Merlos es un interesante episodio de la vida cotidiana y de las argucias de los litígantes para eludir el desafecto de jueces parciales. La acusación que lo llevó ante los tribunales, y que dió lugar a su encuentro y disputas con el fiscal Castilla, muestra al cura Merlos como activo revolvedor de los indios, pues hechos posteriores lo señalan como eclesiástico sospechosisimo a las autoridades reales por su amistad con los famosos hermanos Tornás, Dámaso y Nicolás Catari, que tanta importancia tienen en la historia de los movimientos indígenas en la jurisdicción de la Audiencia de Chuquisaca.

A continuación se esboza un brevísimo derrotero para descubrir las huellas y ahondar en el estudio de la personalidad de Gregorio José dé Merlos.

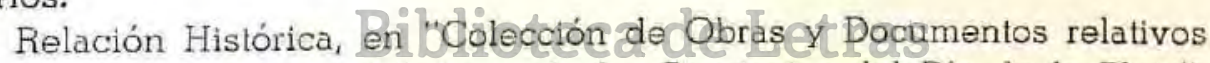
a la Historia Antigua y Moderna de las Provincias del Río de la Plata". publicado por Pedro de Angelis (Buenos Aires, 12. edición, 1836), tomo V. p. 12.

Documentos para la Historia de la sublevación de José Gabriel TupacAmaru, cacique de la provincia de Tinta en el Perú, Ibidem, p. 204-205, (presentación hecha al Rey por Don Tomás Catari); p. 220 (alusiones en la Confesión de Dámaso Calari); p. 251-252 (mención en la Confesión de Nicolás Catari).

Apéndice, en "Tupac Amaru, el rebelde" de Boleslao Lewin: Doc. 9, p. 43; Dóc. 11, p. 424-427 del cura Merlos al virrey Vértiz (de Buenos Aires), escrito en Macha el 14-XI-780; Doc. 12, p. 427-429 de Merlos a Vértiz, escrito en el Convento de Santo Domingo de La Plata el 15-II-781; Doc.

(4) Carta del lltmo. Señor Dr. D. Juan Manuel Moscoso, Obispo del Cuzco al de La Paz, Dr. D. Gregorio Francisco del Campo, sobre la sublevación de aquellas provincias.-Col. Angelis (Buenos Aires 1835), tomo V, p. 156-172. 
13. p. 430, de Vériiz al ministro de Indias don José de Gálvez; Doc. 18, p. 434-438 del ódor Juan del Pino Manrrique a Vértiz, escrito en La Plata el 15-III-781; Doc. 46, p. 465, 468, Representación de Tomás Catari a Vértiz, Macha 12-XI-780.

DANIEL VALCARCEL.

\section{PIDE PROVIDENCIA RECERBADA EN EL. REAL ACUERDO}

El doctor don Gregorio josef de Merlos Curá, $\gamma$ Vicario del Beneficio da Guachácalla de Carangas en la mejor forma que aia lugat en derecho paresco ante V. A., y Digo: que me he adquirido, la adversidad y desafecto dul Señor Don loset de Castilla, Y Caballero fiscal de esta Real Audiencia, por motivos los mas injustos; y que no pudiéndome explicar en la vida pribada, ni en la persona me los manifiesta vivamente en dos pleitos que tengo pendientes en la Curia Eclesiástica, donde unas veses es Protector de los Indios, de los Curatos que anteriormente he serbido $y$ ottas veces es fiscal $y$ acusador.

Discurrí, que la tolerancia, la delerencia, la mediacion de barios respetos, y sobre todo ol rendimiento contrastasen el odio, y mitigasema persecucion. Pero todos estos remedios que en otros animos; y por si solos han sido vastuntes para remober la adversidad, y extinguir el desagrado; han sido nnsuficientes para el Señor fiscal, de quien en mas de un año de persecusiones solo he reclvido convincentes testimonios de que unicamente es su sistema mi destruccion, y mi ruiria.

Para ollo oprimido de la violentiá, lleno de desconsuelos; $y$ sin que lá prudencia me dictase medios para evitar tantos males protexté verbalmento a la integridad de V. A. que en innumerables ocaciones haviän sido mis designios recusar al Señor fiscal, y bajo del mismo concepto pedi, que pasa esta instancià se me nombrase Abogado, y siempre ha sido $\mathrm{mi}$ asunto interponer 10 tecusación en forma, hacierido sobre ello aquellas expreciones que me eran convenientes, $\bar{Y}$ que se persuademed lo letrandeceb cenfenido de mis escritos lo cual executé desengañado de los malos sucesos que havia experimentado por haver abansado los repetidos consejos, que perzonas de honór me dieron para que me baliese de otros medios suabes de aplacát (5) su encono antes de emprehender el de la recusacion.

Llego ya el momento de verificár las protestas con la recusacion que interpongo contra el Ministerio del Señor tiscal en el mas devido modo, $y$ en que es el animo consultar solo, mis defenzas, sin olender a su reputacion o macular su fama ni faltarle a la veneracion y respeto de que tanto me jacto.

Para entablar este remedio me parece, que no es necesario proyanza de cauzas, depocito, ni pena; pues no encuentra mi desbelo ley, ó texto que asi lo prebenga, en las recusaciones que se hasen de los señores fiscales. Anles si beo en los Autores que siendo Virrey destos Reynos el Señor Marquez de Salinas separo a un Señor fiscal de oficio, y sin otro motibo, que decir el acusador que era intimo, y mui parcial dél acusado. Ãsimismo obserbo en sus Doctrinas que por enemistad capital, ó grabe se le segrega al Señor fiscal de la interbencion en las causás. Y que las Reales Audiencias la practican de ofício quando sus pedimentos son nosibos al fisco y al servicio del Rey en lo que proceden conforme al juramento que hasen los Señores Ministros antes de entrar á serbir sus empleos, de que des.

(5) f. 1 v, 
viaran el daño del servicio del Soverano en todo lo posible: y de que se hace cargo la ley 6. titulo 5, 1. 2 de la recopilacion de Castilla.

Todas las que se contienen en el libro 2 tomo $7^{\circ}$ de la misma recopilacion, son las que dan las formas de las recusaciones de los Señores Ministros, y las que prebienen la prueba de causas depocito de maravedices, y execucion de pena. Pero las leyes que unicamente ablan de los señores Oydores que son Jueses no las entienden mis cortas luces de los señores fiscales; que áunque caracterisados posteriormente can el honór de ministros nunca exercen jurisdiccion ni salen de la clase de Procuradores liscales; y Abogados del Rey: contra quienes es bastante la recusacion, $y$ el juramento de calumnia sin que interbenga depocito ni probanza de cauza. Asi śe vé que los Señores Virreyes, y Reales Audiencias, separan de oficio a los Señores liscales, y les prohiven que interbengan en los pleitos. Pero nunca se á visto ni Autor que lo diga el que lo practiquen con los Señores Oydores que son Jueces, y cuia teparacion, exige mas formalidades y requicitos.

Mi tenuidad comprehende que es mas que suficiente insinuar la adbercidad de un Señor fiscal, y el motivo que sea bastante y sin calumnia, de que procede, pară que se le separe (6) de alguna cauza, aunque la manifestacion de su odio no se haga por via de recusacion. sino en un simple pedimento. Lo que tiene maior fuerza cuando las cauzas son escandalosas contra su repulación, y empleo; como verbi gratia, las de ser amacios de alguna muger, pues aun en este caşo estan incluidos los Seriores Oidores; y creo que en ello me conformo con los principios mas conocidos de derecho. Sin embargo expendere el origen de la enemistad ciel Señor fiscal a mi persona, y exsivire los exemplares mas calificados, con que me la ha demostrado; sin apartarme del acatamiento devido a su persona, y de la beneracion que tributo constantemente a su empleo.

Yo paciesco la persecucion del Señor fiscal, solo porque con recato, y la moderacion devida, y desesperado de la demora de mis cauzas en el estudio de este Señor Ministro hablé, lo que toda esta Ciudad dice, con el maior desenfreno, en Plazas, calles; y hasta en el Patio de esta Real Audiencia es decir. Que refiere-al despacho de los prosesos, con insanables perjuicios, que se originan a las paries. Que los Señores fiscales; que han havido en esta Real Audiencia despachaban con maior prontifud que el sentor Don Josel de Casti$\mathrm{Hla}_{\text {; }}$ siendo arsi que tiene cios Agentes, y que sus antesesofes se manejaban con solo uno, trabajando. si, dichos Señores, "perzondmente fedas las vistas. QQUe bl Señor fiscal es parcial de los Oficiales Reales Sierra contra quienes han havido diferentes acusaciones, y denuncias, muy grabes; haviendosele corrido vista de ellas, jamás se ha oido que los acuse sino con apariencia. Que dichos Oficiales Reales, han ultrajado, por escrito a barios de los Señores Oidores, y que el Señor Fiscal no ha hecho la debida insinuación en sus bistas para que estos desordenes se corrijan, y modijeren, lo qual consta en autos. Que al Corregidor de la Provincia de Chichas, Don Francisco Xavier Garcia de Prado, su intimo confidente, le pago el Señor fiscal, por el mez de Septiembre pasado, remitiendole el dinero con un criado español, del actual Corregidor de la Provincia de Yampara Don Francisco Yames barias mulas, que condujeron, unas cargas; las quales por benir con despachos, de que eran do sera, y haberse exparcido en toda esta Ciudad lo contrario: como tambien el que los harrieros, que las condujeron binieron con ellas por el camino extraviado y por donde trancitan los contrabandistas, nombrado Yavisla jurisdiccion del pueblo de Calcha Provincia de Chichas, se sensuró eran de contrabando, y perlenecientes al dependiente del Señor fiscal Don Manuel Romero; lo qual se fundameton con los procedimientos de que los referidos Oficiales Reales tubieron atrevimiento por disuadir, lo que se desia con escandalo publico,

(6) f. 2 . 
no (7) solo de registrar con apariencia $y \sin$ acompañarse con lá jurisdiccion ordinaria. la casa del mencionado Romero. sino también de prebenir ai Señor liscal eta conbeniente hiciesen lo mismo con la de dicho Señor, quien les respondto que eso no lo podia permiltr, si antes no sacaban orden de el Señor Precidente.

Comprovantes de lo reterido han sido el haver el señor fiscal, permitido que los Oficlales Reales comparescan en esta Real Audiencia, a continuat, $\gamma$ acusas a las partes, en las cauzas que de ellos se apelan. lo que ha sido notable desuire suio, y con doño de tercero, porque dicho Señor las debe seguir, por si solo, en las Reales Audiencias. Tambien ha pedido que las cauzas que deben sequirse en esta Real Audiencia, y aun las que estan radicadas en ella so les remitan a los oficiales reales sin repatar en que estos esten reos acusados de las partes, en cuitus causas quiere continuen de lueses como ha sucedido en la de Don Juan Francisco Alvares, en la del escribano Don Justo Cosio, y otras: e igualmente que se buinere la jurisdiccion de! Tribural de esta Real Audiencia atribuiendoles a los Oficiales Reales jurisdiccion que no tienen, como se bé en lá cauza de Don Domingo Fuentes que se sigue ante los Oticiales Reales, diciendo que es extranjero y comerciante: lo que no obstante pide el Señor fiscal se les debuelba para que contimuen como juesea en ellas, valiendose de la Ley que trata de los descaminos.

Tambien se ha visto en lá cauza de flanzas, de los Oticiales Reales de esta Cuidad, y en las del señor general Don Francisco Guemes, pues debiendose seguir, según las leyes, para que no subsista, la Real Haziendo, (8) sin seguridad mas expacio, que el de tres dias que se señale en ellas, para que den nuebos fiandores, el Señor fiscal las ha dilatado tanto con los articulos, que ha promovido, que haviendo pasado muchos meses, no se hallan en estado de que V. A. pueda mandar, lo que deve, á beneficio de la Real hazienda segun consta de los autos de la materia a que me renito. Todo lo referido tiene maior fuerza no solo con la proteccion publica, que el Señor tiscal da à cualesquiera, asuntos, y dependientes a los Oficiales Reales admitiendolos en su casa estando reos, para que jueguen en la meza, que dicho señor se dibierte; sino también con lo que estos le corresponden con barios procedimientos, que se iran publi@ando con eftiempo (9) y entre los cuales me parece bastante expesificar el que acaban de executar nombrando a su dependienta Don Ramon Rometo, pará quje conduscr fos cardales dell Rey de estas cajas, sin que aía dado flanza ni seguridad alguna como siempre se ha executado, $y$ lo que es mas pagandole el dos y medio por ciento, con el titulo de que sea cituadista para conducirlos al Precidio de Buenos Ayres; y que correspondiendo haser el nombramiento de lal Sítuadista a los Oficiales Reales de la Villa de Potosi, ha procedido a ella el Confador Don Lamberto Sierra. con el seguro de que su hermano Don Juan, que lo es de otra Villa, se lo rebalide mediante una carta, que lleba de el Señor Fiscal; en cuio hecho se ha notado que los Oficiales Reales de esta Cuidad, han pasado a quitarlo el medio por ciento de gratificacion al referido Romero, de lo que á dado quejas dicho Señor fiscal, asi pcrque no se le ha esempcionado de esta usurpación, por ser el conductor dependiente suio, $y$ haverles serbido, y protejidolos mucho, como porque se ignora que los de Potosi se acomoden a perdonarles esta propina. y que no la pague por duplicado.

Yo he oido, $y$ sabido, con publicidad lo referido; critique, $\mathrm{y}$ critico, con modestia sobre estos hechos de la misma suerte, que con boracidad lo han hecho otros muchos, y confieso, que he continuado posteriormenie en ello ostigado de las persecuciones del Señor fiscal aun-

(7) f. 2 v.

(8) Tariada la conjunción " $y$ ".

(9) f. 3. 
que persuadiendome. siempre, no llegase a sus oidos, $y$ que en este caso tublese odio solo contra mí, y no contra todia le. Ciudad. En los estados enunciados, y en los primeros que me referido, experimente la mas orrorosa persecucion de dicho Señor contra mi persona, y cauzas, que tenia pendientes; y consultando medios con que rodimirme de sus benganzas resolvi balerme de una muger, que trajo el Señor fiscal, de España, en su compaña a esta Cuidad en el año de 75 por saber era depocito unico de sus obsequios, y distinguido aprecio. Porque notorio es a todo el publico, y no se ocultã à este Superior Tribunal, que con ella sale en coche de quatro mulas dandole, su lado y testera. Que la lleba a las Yglesias. Que la acompaña en los paceos publicos a mula como con Garsilaso, Gallinero. Quirpinchaca, Yotala, y otros. Que de aquí nace séa (10) esta muger unico arcadus por donde logran litigantes detenidos el despacho de sus prosesos. Y que nadie olvidara los dias solemnes de Juevas Santo. y festividad de Guadalupe, en que la citada muger nombrada Josfa, precidio, en la Yglesia Cathedral, a las Señoras Consortes, é hijas de los Se. ñores Ministros, no menos que á presencia de la Real Audiencia, y con aquel escandalo, con que se resintio todo el publico.

Haviendo mis cauzas corrido la desgracia de montenerse retenidas, por muchos meses, en poder del Señor fiscal como un litigante de mi clase, esto es pribado injustamente de su Beneficio. destifuido de facultades, prezo en esta Cuidad por las repetidas instancias del Señor fiscal, perdido el honor por los Supuestos crimenes, que dicho señor me á querido imputar, constituido en la clase de pordiosero, sonrrolandome a pedir a unos, y otros, en el nombre de Dios, me des la limosna, de una misá para mi diario sustento, y por todo to dicho con el maior abatimiento, solo handa en asecho de aquellos arbitrios que remoberan sus males; me parecio conducto ópertuno grangearme el cariño de la mencionada Josefa para estirpar mis padecimientos. Con cuio intento confieso a V. A. que principie a frecuentar la calle del Señor fiscal, y haserle mis expreciones, rendimientos y honestas mira. duras ó por encontrarla diariamente personada publicamente en el balcon de la casa de el exprezado Señor.

Esta continuación de urbanidades y de cue en los mismos teminos fui correspondido por Josefa, hizo al fin la repeticion, que el Señor fiscal se instruiese, de mis comedimientos, $y$ ellos la arrebataron en tâl Zelotipia bl funesta-ira, que desde aquel entonces protextó su odio, que trabajaria en que se me concordase el Beneficio, y en que se berificase mi desgraciada ruina; cuias voces fueron tan notorias, que me consto, llegaron a los pladosoa oidos de todos los Señores Ministros, que componen este regio Tribunal, y que todas las gentes viendome trancitar las calles no täinan otra conversacion que desir: Aquel infeliz ministro de... dicen que el Señor fiscal le ha de concordar el Curato. Contemple la Superior penetracion de V. A. el temerario fundamento de la ojerisa del Señor fiscal tanto mas sensible, quanto ya se conosen los furores de un celozo, y que la ninguna razon, en que estriban tales caprichos, son los que siempre los hasen mas temibles. Consevi por medio de la Josefa (11) lograse un brebe despacho, y solo he verificado enpedernirse el animo del Señor fiscal, y que se inmortalisen mis pleitos con solo el arbitrio de retenermelos.

Si el Señor fiscal sobstiene, sin apariencia, una irreqular zelotipia, aun injuria mas a mi estado, y a mi persona: pues de aquel no son presumptibles desoos tan inhonestos, ni que en perzona del aprecio de este Señor Ministro, se arrojasen mis pensamientos; fuera de que arrimandose al concepto mas piadoso siempre he consevido, que el Señor fiscal por las honrras, y estimaciones que le merese Josefa la tenga en union, virtuosa, y como su

(10) f. 3 v.

(11) f. 4 . 
legitima muger, con todo de que no tiene los atractibos de hermosa. Este ha sido el tono con que me he explicado en las conversaciones privadas, en que ha insidida el consavido usunto, y los demas, que liebo relacionados quejandome a la verdad de que el Señor fiscal me oprime en mis pleitos por una antojadisa zelotipia, a que no he dado merito ni contribuido en lo mas minimo; porque solo fue mi animo atraher la voluntad de Joseia para el pronto clespacho de mis cauzas, y que esto iuese con menos costos, que los que pueden haver tributado otros litigantes desta muger, $y$ a sus dos Agentes en expecial. del que se apellida Sirgado, para el mismo efecto por hallarme reducido a la mátor inopia. O nunca el Señor fiscal hubiera trahido de España semejante muger, o nunca la iubiera en su casa, - nunca la sacara en coche de quatro mulas á su lado, o nunca la trajera en su compaña, en los paseos publicos, a nunca la custodiara hasta en los Divinos templos. Y nunca le dierá señales de la mas idolatrada esposa, para que no tubiese en augmento mis padecimientos, ni encontrase, en el dia, mas enconada la herida; cómo seran presumibles unos desordenados qalanteos en un Eclesiastico Doctrinero, que solo aspita a concluir litijios, restituires a su Beneficio, llenar exactamente su Ministerio, $y$ pensar maduramente en la muerte?. Pero ya son mas riesgesars, para seguir, las explicaciones de la pluma, por lo qual lo mas que no exprimo, comprehendālo la Superior penetracion de V. A. a quien no se ocultan minussias, ni se escapan apises?

Reconocido pues el origen de Aa enemiga grave, y capital que contra mi fomenta el Señor fiscal, demos al precente los calificados hechos. con que la á procurado continuar. Fue el primero asentar en un escrito. que precentó at Provisor $\gamma$ Vicário General de esta Diocesis, $Y$ en otro, que produjo ante el senor Obispo de la Paz, como Juez delegado de apelaciones, el que seria su asunto tratar por cuerda ceparadá de la llegitimidad, con que obtube el Curato de Calcha. Como si este (12) intento fuese conducente a la proteccion que hace a los Yndios en áquella cauza, ó cono si el Señor fiscál tublese derechos para redarguir de insubsistente, la Real Precentacion, que obtube de dicho Beneficio, y en la que se procedio del modo mas arreglado, $y$ legitimo pasandole el actual M. Y. S. Precidente, un recado, que lo $11 \mathrm{bog}$, su Asesor General Doctor Dop Vicente Tardio, al Señor fiscal, que en aquel entonces 10 era (y que igualmente se havia declarado mi capital enemigo por motibos que ahore no es Diermo de ekplicerlost.cel Señor Don Tomas Alvares de Acevedo, prebiniendole, si hallaba algun inconveniente, en que yo fuese promobido del Benefício de Coromá, que obtenia, a el de Calcha, que obtube: y respondiendo dicho señor que ninguno havia; se me precento por el exprezado Señor Vice Patron.

Esta protexta bertida en aquel escrito no ha tenido embaraso el Señor fiscal de proferirla en las conbersaciones mas publicas, con la absoluta de que no pararia hasta concordarme el Curato; $y$ en que debo adbeitir; que haviendo pasado a su Casa Don Martín Boneo Corregidor Provisto, de la Provincia de Porco, con el destino de templarle el enojo. Y retraerlo del destino de su injusta zelotipia, las expeciones que le hizo fueron; de que yo era el clerigo mas criminal, y escandalozo, que havitaba estos lugares; y que tubiese entendido, que si me oponia a los Curatos bacantes, manifestária los obises, que me asistian, para que se me diese beneficio; motibo que me hizo ceparar del propocito. en que estaba de haser oposicion en aquel concurso, por lo poco que acomoda á mi salud, (en eslos ultimos tiempos) muy quebrantado, la puna rigida de la Doctrina que al precente obtengo. Y siendo estas expreciones del Señor fiscal. y sus urgentes deseos, de mi destruccion unos rasgos proprios de el exsaserbado odio, que me tiene: no puedo dar de ello casos mas concluientes, que los que ministran sus escritos, y la respuesta dada al Corregidor Boneo.

(12) f. 4 v. 
En Auto de 20 de Maio del año pasado de 75 nombró (13) V. A. de Protector de los Indios, en la cauza de Calcha, al Doctor Don Marcos Caballos, Abogado de esta Real Audiencia. y con todo el Señor fiscal se introdujo en ella a ser Protector conira lo que le ordena la Ley 39. libro 2. titulo 18 de Indias, $y$ sin reparar en la mostruosidad, que resultaba de defender en un proprio juicio a unos Indios, a quienes el acusaba en esta Real Audiencia. Un proceder incompatible, y contrario a ley expreza manifiesta bien el termino a donde llegá el sumo odio que el Señor fiscal profesa a mi perzona; $y$ en que haviendo ocurrido a la justificacion de V. A. para que declarase que no podia interbenir en la cauza de Calcha como liscal para acusar a los Indios, $y$ al mismo tiempo como Proteclor para haser a fabor de ellos, y en mi contra su defenza: aunque en Decreto de 26 de Octubre se declaró el impedimento legal que tenia en la materia, y que continuase de Protector el Doctor Ceballos; no obstante salio pidiendo, el que siquiera se le permitiese el haser de fiscal porque como interbengá contra $\mathrm{mi}$ en la cauza poco le importa al Señor fiscal que sea con cualquiera inbestidura. Que pruebas mas reales puedo dar á V. A. de la adbersidad, y desafecto, que sobstiene contra mi indibiduo?. Repare V. A. el deseo de este Señor Ministro que se endereza, a que solo las cauzas dél mas avatido sacerdote, se substancien con dos fiscales criminales a saver, con dicho señor y con el Promotor fiscal ecleciastico, que tiene la Curia Arzovispal donde tengo radicadas mis causas?. Pregunte V. A. al Señor Don Josef de Castilla si el celo, que afecta en mis pleitos; es el mismo con que entra en tas muchas cauzas, que ay de capitulos contra otros Doctrineros?. No por cierto, y descle ahora respendo yo a V. A. a nombre de dicho Señor, que en la ócacion precente ay barias, $y$ en ninguna se bé, que en calidad de fiscal, no pudiendo interbenir en la de Protectór, haia entrado ni entre, ¿Que odio mas declarado, quiefe V. A, que manifieste el Señor fiscal que el que acreditan los referidos procedimientos?. Ya dije d́ V. A. (14) en uno de mis rendidos es. critos, que no pararia hasta hechäme personalmente a los pies de mi Soverano, y creo se berifique, porque la persecucion de este Señor contra mi honor, y árreglada conducta la contemplo inmortal; $\gamma$ de paso diré á V. A. que no han faltado perzonas, que atimidandome con el poderio de dicho Señor han procurado retraherme de eharvitrio unico pata lograr, el curzo de mis cauzas, de esta Reeusacion. Pero como soto temo á Dios al Rey, y á mis delitos, y me hallo destucibg de los quème imputan the respondido con el ayre que me presta la Justicia, que el caso ya no tiene remedio; pues haviendome balido de los medios mas prudentes é imág̣inables, $y$ no haviendo podido recabár nada con ellos, ya no me quedaba otro que el de la Recuzacion.

En las Leyes de los Titulos 59 y 18. Libro 2, de Indias se ordena a los Señores fisca. les, no detengan los pleitos, ni dilaten los Prosesos, no embarganle esto el Señor fiscal obserba la conducta de demorar los mios, y también los de otros en su estudio, con el solo fin de periudicarme, y poner en execucion la adusta ojerisa, con que me mira. La integridad de V. A. ha mandado por repetidas providencias, que debuelba al oficio del precente Escribano de Camara los autos de las Docirinas de Coroma y Calcha. Pero al Señor fiscal no le hasen fuerza las ordenes del Rey en sus Leyes, ni los mandatos de un Tribunal que lo representa, y continuan los prosesos en su poder, porque asi lo quiere el odio, y lo apetese la injusta zelotipia.

Por la ley 76. libro 19. tomo 13. de Indias esta desidido que los Beneficios Curados, solo admitan Coadjutores ó Curas en el interin por el trmino de quatro meses, y sín otro espíritu, que el que las Doctrinas no carescan de su legitima Cura, Con que si en todos

(13) f. 5.

(14) f. 5 v. 
titigios ordena el REY que sus fiscales los despachen con anticipacion $y$ prontitud, qué se dira de un juicio, en que es el interesado un Cura? que no puede estat ceparado de st. Benelicio por mas termino, que el de quatro meses, y en que ya quito de segregacion el plano de mas de tres años? Yo no tendría arfojo pata decir, que a th saviduria del Señol fiscal se oculten estas Leyes $\gamma$ estando en el concepto opuesto debo conchur, que teniendolas precentes no pide su cumplimiento por lá desordenada, enemistad con que me mirá. Fue providencia de V. A. que cierto testimonio lo agregase el Provisor a la calaz de Calcha; Y luego que tubo noticia de ello el Señor fiscal salio pidiendo uaslado, en un punto que no era parte ni podia haser oficio de Protector; $\gamma$ lo notable es, que pluesto el expediente (15) en su poder le hizo expecial encargo a su solicitadot Docior Don Pudio de Aresmendi, de que me acusase en las terminos mas agrios y fuertes que fuesen asequibies. Pero representandole este juisioso Abogado, que no encontraba jurisprudencia para semejante intento, ni menos para que el Señor fiscal hiciese de Protector contu to desidido en la ley de Indias, le ofrecio, el que para ello le daria Doctrina, $y$ que fiando este elrecimiento en el Paiz de las promesas logro ínalmente este Solicitador separarse de la incumbencia, y no grabar su conciencia en tán espinosa, y delicada materia.

Subrrogase à esto el Licenciado Don Jorgs Delgadillo, en quien andan paralelas la extraccion obscura, y la malignidad suprema, con la dulacion serbil, y supina ignorancia de derechos. Y asi conviniendo con las ideas del Señor fiscal salio pidiendo, que la cauza de Caicha se acumulase a la de Coroma, y que aunque esta estaba conclusa no solicitaba en ella cosa alguna hasta que la otra se hallase en fos mismos terminos. ¿Donde se havra visto conducla tan inhumana, ni modo de proceder tan extraviado? Pues que motibo havia, para que se suspendiese la resolucion de Coroma por solo esperar la substansiacion del plei. to de Calcha? Las dos cauzas son inconecsas, y no tienen dependencias, $y$ el quererlas unir el Señor fiscal con su Delgadilio solo fue por mortificarme, y poner en uso su intole. rable advercidad a mi persona; siendo evidente que aunque los dos litijios fuesen co necsos, y dependientes, el Señor fiscal no era parte en el de Calcha, y asi no podia pretender, que la Sentencia de un pleito concluso. se detublesep por la que se aguardaba de otro, en que no estaban empleadas las formas, y tramites de la substansiacion.

El hecho de haver ifistado of Senof fiscal al doctor Aresmendi a que me acusase rigurosamente en la cauza de Calcha, y respondido este que no lo podia practicar en conciencia; es de los mas notorios; porque lo exprezó a muchos sugetos caracterisados, $y$ entre ellos al Doctor Escurra, Dor. Ormachea, Dor. Warnes, Dor. Chabarria, y a Don Juan Joset Gil Administrador de la Real Renta de Tabacos de está Ciudad; y quienes tubieron motibo de instruirse en este concepto por hallarse empeñados de mi parte a fin de que me proporcionasen el mas pronto despacho de el Solicitador, y que me dificultaba el Señor fiscal.

Logro la satisfaccion de que no dirá el Señor fiscal, que en el remedio de recusarle procedo de ligero, pues para lograr brebe despacho, y remover el retardo me vali, primeramente de quantos intercesores, y medios me pudo dictar la prudncia. Interpuce prime. ro el Superior respeto del Señor Precidente de esta Real Audiencia (16) quien por mano del Doctor Don Vicente Tardio me respondio haverse insinuado con el Señor fiscal. Me vali posteriormente del citado Corregidor de Porco, y de Don Juan Ántonio de Acuña (17)

(15) f. 6 .

(16) f. 6 v.

(17) Fué muerto en represalia de haber mandado asesinar a Tomás Catari, cuando con. ducía preso a éste y cayó en una emboscada el 9 de enero de 1781 ( $v$. "La rebelión de Tupac Amaru" p. 16-17). 
que lo fue de Yampara, $y$ aunque a todos ofrecio el Señor fiscal despacharme prontamente, solo se quedó la coza en espectacion y promesa aunque todos fueron adbertidos del desafecto notorio a mi persona por mal fundados quentesillos, que los expliqué en general resarbando en $\mathrm{mi}$ el negocio de la zelotipia.

Otra cauze, que puntualisa muy al vibo el odio del Señor fiscal, es el modo injurioso. y lleno de dicterios, con que en sus respuestas trata a mi persona, sin hacer concideracion de la Ley Real de Parlida, que le ordena el maior respeto a los Sacerdotes; y que zun los Jentiles lo tribulaabn, con el maior cuidado, a los suios. ¿Y que dira V. A. quando registre los pedimentos del Señor fiscal y encuentre que no me da el tratamiento do Doctor y Don. devido a mi grado, estado, empleo, y conosido illustre nacimiento; registrense los autos, que contienen mis causas, y los seguidos sobre la sublebacion de Calcha, en este Superior Tribunal, y a primera vista encontrara V. A. comprobado lo referido?

Esmerado empeño ha sido el del Señor fiscal el pedir instantaneamente testimonio de qualquier documento con que presuma poderme haser las mas agrias acusaciones. Asi teniendo noticiá, de que tres testigos viles, enemigos mios, y de deprabadas costumbres procuraban implicarme en los ordenes que se dieron en el amotinamienio de los Indios do Calcha, pidio sin perdida de tiempo testimonio de la Sumaria, y adbertido de ello, represente. que no devia sér diminulo, como lo solicfitaba el Señor fiscal sino integro. y como lo mandaba la Ley de Indias, es desir, que no solo se le diese de la citada iniormacion sino tambien de las demas sumarias existentes en esta Real Audiencia y por las que se calificaba, el arreglo de mis operaciones, la (18) rregularidád de mi conducta, y mi perfecta indemnidad, en los mobimientos, y ordenes (19) expedidos en Calcha. Mandolo asi la integridad de V. A. y de ello se deduce, que como la prontitud del Señor fiscal on pedir testimonios diminutos acredita su odio, asi juntamente el conbenir yo en que se le dén integros, persuade mui a fondo la justicia que fomento sin haverle pedido al Señor tiscal otro fabor con mis intersesores, que el brebe despacho, que le encargan las Leyes; pero no algun suplemento o gracia, que a la berdad no nesecito; $y$ en que es indispensable notar, que luego que se mando por Y A. Jos testimonios fuesen integros, za que el Señor fiscal abandono el propocito, porque su sistema es scuscr, con testimontos truncos, y furtibos, no con

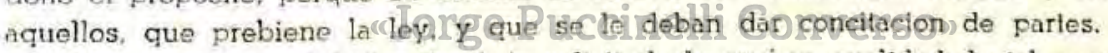

Interpuesta por el Señor ifscal, la solicitud, de que en qualidad de tal. y por la vindicta publica debia interbenir, en la cauza de Cálcha, lueqo que la Soberania de V. A. probeio el Auto de 27 de Septlembre, y probino en el, que lo podia haser segun derecho; en ese mismo dia. a las tres y media de la tarde salio pidiendo al Señor Apostólico, que mandase entregarle los autos de Coroma y Calcha, con el protexto de conbenir, asi al servicio de S. M. y desagravio de la vindicla publica. Y conseguido el designio; el servicio del REY, y vindicla publica han sido tener retenidos los prosesos, por el largo tiempo de mas do dos meses, para que no logren progreso, ni yo consiga, el que se me sentencie la cauza de Coroma, ni pueda practicar mis defenzas en la de Calcha. De forma, que el Señor fiscal os on esta Corthe el arvitro unico de los pleitos, y de su mano pende, el que logren ó no seqü@la.

Un caso notable presentan mis cauzas, y digno efectibamente de refleccionarse por la Superior concideracion de V. A. En el Septiembre u Ociubre del año pasado de 775 se le pasaron al Señor fiscal en vista los aufos de Coroma; $y$ haviendo respondido a ellos con la puntualidad que acoslumbra, quiero decir el dia 16 de diziembre le prebine a su Solici-

(18) Tariada la letra inicial " $i$ ".

(19) f. 7 . 
tádor Doctor Don Pedro Aresmendi, que no los pusiese en el Jusgado Eclesiastico hasta el 23, en que se serraba el punto por caer la Pasqua de Navidad on dí lunes, y lograrse uno mas con el Domingo, Hizolo asi el Solicitador, y haviondo el mismo dia por la mañana, dado mi respuesta, $\gamma$ conseguido, que el Proseso se le pasase incontinenti al Señor fiscal con todo saco certificacion (20) de los notarios de que en su poder no quedaban algunos autos, $y$ despues de la suposicion temeraria, que por respelo a su Ministerio como. tieron estos oficiales, tambien dejó autentisado el estraño modo, con que se piden. $y$ se den semejentes certificaciones.

Finalmento la enemistad del señor fiscal contra mi persona es caphal, o quando menos de las más grabes. Las amenezas que mo ha hecho de perderme, y concordarme el Beneficio son notorias a todo el público, y tambien a V. A. iqualmente la es, que pide en mis pleitos por venganze, y no por justicia. Que procede en ellos apacionadamento. Y que su distinguido Ministerio solo es un pretexto de quo se vale, para ocacionarme perjuicios, y llobarme a la mas lastimosa ruina.

La Real Piedad del REY solo se ha desvelado en subvenir a litigantes oprimidos con el remedio llano de la recusacion. y para mi seria de notable perjuicio que el Señor fiscal contínuase en mis cauzas con esta investidura, ó con la de Protector, siendo evidentemenio mi capital Enemigo, y grabe desafecto: has cauzas relacionadas son mas que suficientes, para que se le copare, de que interbenge on estos litigios. Ya se á fundado que ni se deben probar cauzas, verificarse depocilo ni executar peno. por sér este un pribilegio. que dan las Leyes de Castilla a los señores Oidores como jueses, y no a los Señores fiscales. Se ha convensido contextos. y exemples ló has soiemnng çue ins señoree virueyes, $\gamma$ Rna. les Audiencias los pueden ceparar, y separan de oficio on los pleitos por la enemiga de. clareda a las partes, $\dot{0}$ por otras concideraciones. Pues principia de derecho incontextable, que es mas facil, $y$ se nesecita de menor enemiga para recusar a un Señor fiscal, que para excluir a un teatigo, a quien se le pone la nota de enemigo. Pero si lo fundado no fuese bastante, ni quadrase a la Superior integridad de V. A. debere reprecentar, que por la Ley 5. titulo 10. libro 2, de Castilla jesta probenido que el cecusante, pobre, no sea apremiado. á herificar el depocito. ni a pagar la pena, y que viste, ot quo se obligue á hacerlo quando

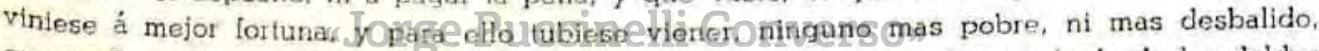
que un Beneficiado pribado de su Doctrina por el lermino de tres años, grabado de los dobles gastos, que ocasionan los lítigios, que ocho años hä sigo en recuperacion de mi honor, y fama, cituado on un (21) territorio estraño, y embargadas, on fin, sus utilidades, y probentos por los empeños que le han sido inhovitables hasér para sus presisos alimentos. Estas estrecheses puedo decir que a nadie se le ocultan, por sér tan manifiestas, y quo me las ha cauzedo el Señor fiscal. Pero con todo las recomiendo esi a la Superior Clemencia de V. A.

La ley real de Castilla ordena que estos Fecursos se produscan con firma de Abogado. Y aunque, para ello pedi se me destinase uno, y V. A. nombró al Doctor Don Joaquin Benito Laredo se excusó este por las incidencias que trabe con el Señor fiscal. cuia escusacion Se tubo por lejitima, $\gamma$ se le hubo por coparado del nombramiento. En esta inteligencia. yo no encuentro Letrado que firme el pedimento, porque todos temen al Señor fiscal, y recelan ser victimas de su oncono, y resentimiento. Si yo con sér Eclesiastico, no me hs libertado de sus persecuciones, qué no sospechará un lego, en quien es mas proporcionable la satisfaccion, y venganza, por el daño que puede inferirle el Señor fiscal por si solo?

(20) $1.7 \mathrm{v}$,

(21) f. 8 . 
Nada es mas frequente en el Señor fiscal que el hacer amenasas quando consibe, que se le falta en lo mas minimo, ó se le óponen à sus deceos. Comprobante de ello es la cauza del Doztor Laredo, pues por haver interpelado á V. A. sobre el brebe curso de los autos expuso el Señor fiscal que en pena de ello no los havia despachado. Así qué Letrado sera tan animoso, que se atreba á firmar la recusacion sino interbiene un estrecho mandato de V. A.?, el que sin duda se debera berificar, si se contempla presisa, la firma de Letrado, conviniendo yo desde aora, con el que nombrase V. A. para que subscriba este escrito, si acaso no se hace concideracion a todo lo que solidamente llebo fundado, y al allanamiento del Señor fiscal, y en que convino lo precentase sin firna de Abogado; sirbiendose V. A. mandár separase, en este caso, conira el qual dedusco los dereçhos expresados por via de instruccion, esla representación al Abogado que se asignase, a fin de que arregle el escrito en forma; sin omitir, cauza alguna, que sea conducente, $y$ se halle contenida en este recurzo; por lo que, $y$ haciendo el recurso mas conbeniente, que he aqui por expreso con la reiterada protexta de no ofender en lo mas lebe al Ministerio del Señor fiscal $\mathrm{y}$ antes si prestarle mi mas profuncla veneracion y acatamiento.

A V. A. pido $y$ suplico que haviendo por interpuesto dicha recusacion (22) se sirba ceparar al Señor fiscal de la interbencion en mis cauzas en la conformidad que llebo pedido. Y declarando, en caso contrario, si estoy obligado a probár cauzas, afiansarlas, y precentar escritos con firma do Abogado en la recusación al Señor Fiscal, sin hallarse estas cualidades odiosas, determinadas en las Leyes del Reyno: $y$ en este ultimo caso mandár, se forme, y firme por un Abogada el escrito con la agregagion de mi firma; $y$ juro in verbo sacerdotis taclo pectore no procedér de malicia sino por alcanzar justicia; dandoseme los testimonios, que pidiese de este oscrito y su proveido. y de todo el expediente de reçusacion, para ocurrir al Excelentisimo Señor Virrey de estos Reynos y al REY en su Supremo, y Real Consejo de las Indias, á demandar, los periuicios, atrasos, y menoscabos, que me ha inferido el Señor fiscal, y para ello.

Otro si a V. A. pido $\gamma$ suplico que respecto de que todas las cauzas, que califican la enemistad, $y$ odio del Señor fiscal emanan, y so deducen de los Aulos de Coroma, y Calcha, que meses ha retiene en sulpeder diche Señor Minste. con todo del Superior

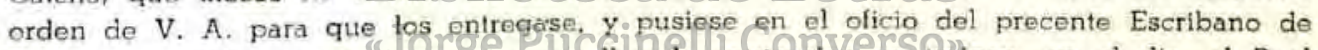
Camara; se sirba mandar, que para tesolber fa recusaciofe se Paigan, en el dia, al Real Acuerdo. y asi mismo los formados aserca de la sublebacion del Pueblo de Calcha, y los que sigo on esta Real Audiencia sobre que ni como fiscal ni como Protector interbenga en mis cauzas el Scñor Don Josef de Castilla pido justicia ut supra.

(fdo.) Dn. Gregorio Jose de Merlos.

Otro si a V. A. pido y suplico que respecto de haverseme ministrado reciente noticia de haver debuelto el Señor fiscal los autos relatibos a las Doctrinas de Coroma y Calcha, al Jusgado del Señor Juez Delegado de Apolaciones contra el expreza mandato de esta Real Audiencia en que (23) se prebino se pusiesen, estos, en poder del Escribano de Camara para tomar en vista de ellos, la providencia mas arreglada a juslicia y que por su contexto, y actos progresibos. resultan los meritos lejitimos que existen para la recusacion interpuesta contra el Señor fiscal. y para que asimismo se le cepare, de plano en todas mis cauzás, ó

(22) 1. 8v.

(23) f. 9. 
ora sea como Protector ó como Fiscal, como se tiene íundado. Se sirba mandar que por dicho Escribano de Camara, $y$ de orden de este Superior Tribunal se pase oficio a dicho señor Juez Apostolico para que se entreguen los Autos. y se traigan a esta Real Audien. cia a fin de resolber, con su inspeccion, el importante, $\gamma$ urgente articulo de la recusacion: y en que protexto a $V$. A. haver procedido muy circunspecto en la exsivicion de las causas, que lejitiman este recurzo, pues me sobran muchas, en copioso numero, $\gamma$ que no expendo por no dilatár mis defenzas pues siendo comunes las quojas que se exsalann contra el Señor fiscal, á cada individuo dél Pueblo, a quien participo la tecusacion es un ollente mio, de sumo gusto, y tambien el que me ministra una rueba cauza acaesida contra el, y que no havia llegado a mi noticia: pido justicia ul supra: (enire renglones -ol- ommendado $\rightarrow$ - vale - testado- y s- no valo).

(fdo.) Don Gregorio joseph de Merlos.

Yo Feliz Paravisimo, Escriváno de Su Magestad. Certifico, Y doi fe que el Doctor Don Gregorio Jph De Merlos, Cura y Vicario del Beneficio (24) de Guachacalla de Carangas, concordó, y corrigió en mí precencia y la de los téstigos de oficio, quatro escritós do él mismo thenor de esle, firmandolos ante mi, y ge halairon concordes: $y$ el uno lo precentó oi dia do la tha. a la Real Audiencia, y los otros tres los recervó en ssi, para los efectios que io comvengan; Y para que constte lo cerfificico en la Ciuclad de la Platta, en sinco dias del mes de Dissiémbre, de mil Setteciontos. setlentla y geis: siendo lestigos Dn. Valentín Rodriques; y Marco Paravíssino.

En tesstlimonio

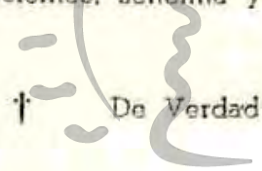

Feliz Paravíssino.

Essno. De S. M.

\section{Biblioteca de Letras}

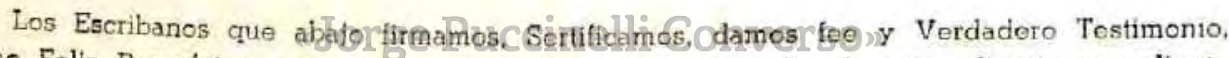
cómo Feliz Paravísino, por quien parece Signado y firmado el anttocodientte expediente as tal Escribano de S. Mag, como se Titula, fiel, legal, y de toda' Confianza, y que a sus Semejentes (25) se les ha dado, y dá entera fee y Creditto en Juicio y fuera de el, $y$ para los efeclos que haya lugar damos la presente en esla Ciudad de la Platta; en diez y Siotie dias del mes de Diziembre de mil Settecientlos Seltentla $y$ Seis años.

Martín Joseph de Terrasas

Escribano de S. M. Público y de Cabildo
Joachin Guerra Michel

Escribano de S. Mag. Público.

(24) f. 9 v.

(25) f. 10. 